\title{
Accuracy of Bolus and Basal Rate Delivery of Different Insulin Pump Systems
}

\author{
Guido Freckmann, MD, Ulrike Kamecke, MEng, ${ }^{1}$ Delia Waldenmaier, MSc, \\ Cornelia Haug, MD, and Ralph Ziegler, $\mathrm{MD}^{2}$
}

\begin{abstract}
Background: Insulin pumps are used for basal rate and bolus insulin delivery in patients with diabetes. In this in vitro study, accuracy of delivery of different commercial insulin pumps was evaluated.

Materials and Methods: Accuracy of 10 different insulin pump systems (5 durable pumps with different insulin infusion sets and 1 patch pump) was tested with a microgravimetric method. Mean bolus accuracy of 25 successive $1 \mathrm{U}$ boluses and of 12 successive $10 \mathrm{U}$ boluses was assessed, and delivery time for $10 \mathrm{U}$ boluses was measured. Basal rate accuracy at $1.0 \mathrm{U} / \mathrm{h}$ was evaluated for $72 \mathrm{~h}$ and for individual 1 - $\mathrm{h}$ windows.

Results: Mean bolus delivery was within $\pm 5 \%$ of target for both tested bolus sizes, but precision of individual boluses was higher with the larger boluses. Delivery times varied between the different pump models but agreed with the specifications of the respective manufacturers. Regarding basal rate accuracy, the total deviation for $72 \mathrm{~h}$ was very small in all pumps; however, larger deviations were observed during the first $12 \mathrm{~h}$. For the patch pump, large variations between individual 1-h windows were observed.

Conclusions: In general, all compared insulin pump systems showed a similar level of accuracy. Differences, especially between durable pumps and the patch pump, were observed when considering each hour of basal rate delivery separately.
\end{abstract}

Keywords: Continuous subcutaneous insulin infusion, Insulin pump, Accuracy, Basal rate, Bolus.

\section{Introduction}

C Ontinuous SUbCUTANeous INSULIN INFUSION (CSII) therapy is indicated for people with type 1 diabetes who fail to achieve an adequate glycemic control with multiple daily injections (MDI) and who are able and motivated to intensively manage their therapy, and for selected people with insulin-treated type 2 diabetes. ${ }^{1}$ Especially when combined with continuous glucose monitoring, it is an efficient and the most physiological therapy option with many benefits. ${ }^{2}$ Common insulin pumps allow a more flexible therapy than MDI, including a variable basal rate and different bolus types, and in one study they have been shown to deliver insulin more accurately than syringes or insulin pens. ${ }^{3}$ Yet, differences in delivery accuracy between available pumps have been reported, especially when comparing durable pumps to patch pumps. ${ }^{4-7}$ Regarding accuracy, one has to distinguish between bolus accuracy, when a rather large volume is delivered within a short time, and the quasicontinuously delivered basal rate accomplished by repeated small short bursts. In addition, the accuracy of an insulin pump depends among others on the actually used bolus or basal rate size and probably also on the used insulin infusion set (IIS). Furthermore, experimentally assessed accuracy

\footnotetext{
${ }^{1}$ Institut für Diabetes-Technologie, Forschungs- und Entwicklungsgesellschaft mbH an der Universität Ulm, Ulm, Germany.

${ }^{2}$ Diabetes Clinic for Children and Adolescents, Muenster, Germany.

Data included in this article were presented, in part, at the 42nd Annual Conference of the International Society for Pediatric and Adolescent Diabetes, October 26-29, 2016, in Valencia, Spain; the 16th Diabetes Technology Meeting, November 10-12, 2016, in Bethesda, MD; the 10th International Conference on Advanced Technologies and Treatments for Diabetes, February 15-18, 2017, in Paris, France; the 11th International Conference on Advanced Technologies and Treatments for Diabetes, February 14-17, 2018, in Vienna, Austria; and at the 78th Scientific Sessions of the American Diabetes Association, June 22-26, 2018, in Orlando, FL.

(C) Guido Freckmann, et al., 2019; Published by Mary Ann Liebert, Inc. This Open Access article is distributed under the terms of the Creative Commons License (http://creativecommons.org/licenses/by/4.0), which permits unrestricted use, distribution, and reproduction in any medium, provided the original work is properly credited.
} 
Table 1. Tested Insulin Pump Systems

\begin{tabular}{|c|c|c|c|c|c|}
\hline $\begin{array}{l}\text { Pump } \\
\text { system }\end{array}$ & Insulin pump & Manufacturer & Infusion set & Cannula & $\begin{array}{c}\text { Tubing } \\
(\mathrm{cm})\end{array}$ \\
\hline AI-F & Accu-Chek ${ }^{\circledR}$ Insight & Roche Diabetes Care GmbH, & Accu-Chek ${ }^{\circledR}$ Insight Flex & $6 \mathrm{~mm}$ Teflon & 40 \\
\hline AI-R & Accu-Chek Insight & Mannheim, Germany & Accu-Chek ${ }^{\circledR}$ Insight Rapid & $6 \mathrm{~mm}$ Steel & 40 \\
\hline ASC-F & Accu-Chek ${ }^{\circledR}$ Spirit Combo & Roche Diabetes Care GmbH, & Accu-Chek ${ }^{\circledR}$ FlexLink & $8 \mathrm{~mm}$ Teflon & 60 \\
\hline ASC-R & Accu-Chek Spirit Combo & Mannheim, Germany & Accu-Chek ${ }^{\circledR}$ Rapid-D Link & $6 \mathrm{~mm}$ Steel & 50 \\
\hline AV-I & Animas ${ }^{\circledR}$ Vibe $^{\circledR}$ & $\begin{array}{l}\text { Animas Corporation, Inc., } \\
\text { West Chester, PA, USA }\end{array}$ & inset $^{\mathrm{TM}}$ II & $6 \mathrm{~mm}$ Teflon & 60 \\
\hline M6-Q & MiniMed $^{\circledR} 640 \mathrm{G}$ & $\begin{array}{l}\text { Medtronic MiniMed, } \\
\text { Northridge, CA, USA }\end{array}$ & MiniMed $^{\circledR}$ Quick-set $^{\circledR a}$ & $6 \mathrm{~mm}$ Teflon & 46 \\
\hline MO & mylife $^{\mathrm{TM}}$ OmniPod ${ }^{\circledR}$ & $\begin{array}{l}\text { Insulet Corporation, Billerica, } \\
\text { MA, USA }\end{array}$ & - & $6.5 \mathrm{~mm}$ Teflon & - \\
\hline PV-M & Paradigm $^{\circledR} \mathrm{VEO}^{\mathrm{TM}}$ & Medtronic MiniMed, & MiniMed $^{\circledR}$ Mio $^{\mathrm{TM}}$ & $6 \mathrm{~mm}$ Teflon & 46 \\
\hline PV-Q & Paradigm VEO & Northridge, CA, USA & MiniMed Quick-set & $6 \mathrm{~mm}$ Teflon & 46 \\
\hline PV-S & Paradigm VEO & & MiniMed $^{\circledR}$ Sure-T ${ }^{\circledR}$ & $6 \mathrm{~mm}$ Steel & 46 \\
\hline
\end{tabular}

${ }^{a}$ The batch used in this study was recalled by the manufacturer (Medtronic reference FA785) after the investigation. The results did not indicate any malfunction of the infusion sets used in this investigation; all product names and trademarks are the property of their respective owners.

Table 2. Bolus Accuracy: Mean Deviation from Target and Percentage of Individual Boluses Within $\pm 15 \%$ of TARget For $1 \mathrm{U}(N=225$ Boluses) AND $10 \mathrm{U}$ Boluses $(N=108$ Boluses)

\begin{tabular}{|c|c|c|c|c|}
\hline \multirow[b]{2}{*}{ Pump system } & \multicolumn{2}{|c|}{$1 U$} & \multicolumn{2}{|c|}{$10 U$} \\
\hline & Mean deviation $\pm S D$ & $\begin{array}{c}\text { Individual boluses } \\
\text { within } \pm 15 \%(\%)\end{array}$ & Mean deviation $\pm S D$ & $\begin{array}{c}\text { Individual boluses } \\
\text { within } \pm 15 \%(\%)\end{array}$ \\
\hline AI-F & $+0.5 \% \pm 3.5 \%$ & 100.0 & $+0.3 \% \pm 1.1 \%$ & 100.0 \\
\hline AI-R & $-2.4 \% \pm 2.8 \%$ & 100.0 & $+0.4 \% \pm 0.9 \%$ & 100.0 \\
\hline ASC-F & $-0.6 \% \pm 1.9 \%$ & 100.0 & $-0.6 \% \pm 0.9 \%$ & 100.0 \\
\hline ASC-R & $-0.3 \% \pm 1.9 \%$ & 100.0 & $-0.6 \% \pm 0.8 \%$ & 100.0 \\
\hline AV-I & $-0.2 \% \pm 2.1 \%$ & 99.6 & $-0.9 \% \pm 0.6 \%$ & 100.0 \\
\hline M6-Q & $+0.6 \% \pm 2.6 \%$ & 100.0 & $-0.7 \% \pm 0.6 \%$ & 100.0 \\
\hline MO & $+0.0 \% \pm 12.5 \%$ & 76.9 & $+0.3 \% \pm 0.7 \%$ & 100.0 \\
\hline PV-M & $+0.6 \% \pm 2.1 \%$ & 100.0 & $-0.8 \% \pm 0.9 \%$ & 100.0 \\
\hline PV-Q & $+0.3 \% \pm 3.3 \%$ & 99.6 & $-0.5 \% \pm 0.9 \%$ & 100.0 \\
\hline $\mathrm{PV}-\mathrm{S}$ & $+1.2 \% \pm 1.7 \%$ & 100.0 & $-0.5 \% \pm 0.9 \%$ & 100.0 \\
\hline
\end{tabular}

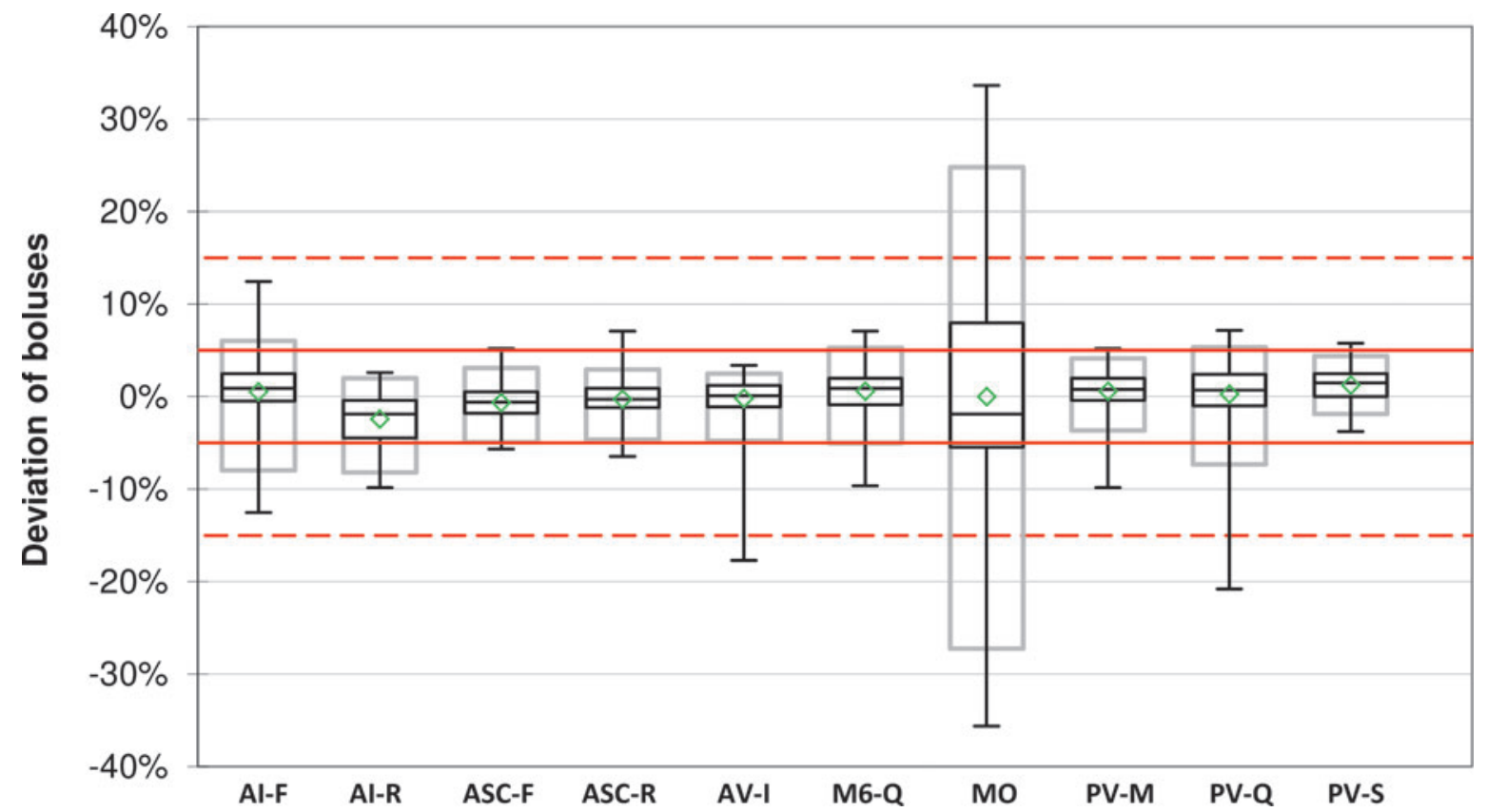

FIG. 1. Bolus accuracy for $1 \mathrm{U}$ boluses. For each system, mean (green diamonds), median with first and third quartile (black boxes), minimum and maximum (antennae), and 95\% range (gray boxes) are shown ( $n=225$ boluses). Red lines and red dashed lines indicate target $\pm 5 \%$ and target $\pm 15 \%$, respectively. 


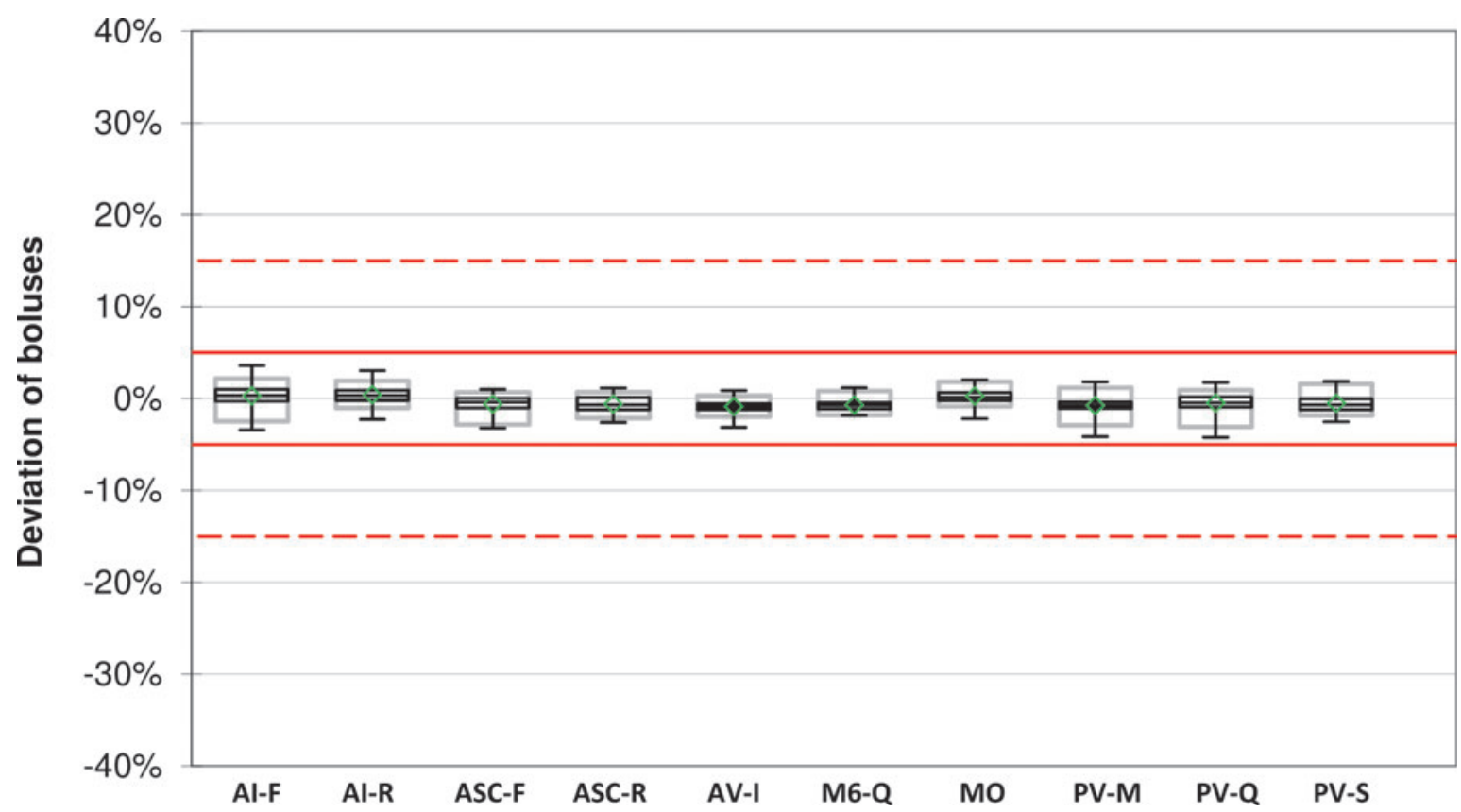

FIG. 2. Bolus accuracy for $10 \mathrm{U}$ boluses. For each system, mean (green diamonds), median with first and third quartile (black boxes), minimum and maximum (antennae), and 95\% range (gray boxes) are shown ( $n=108$ boluses). Red lines and red dashed lines indicate target $\pm 5 \%$ and target $\pm 15 \%$, respectively.

might be influenced by an adequate test setting. The latter has previously been intensively discussed and was, therefore, addressed separately by us. ${ }^{9}$ In this study, accuracy of bolus and basal rate delivery was tested in vitro based on IEC $60601-2-24^{8}$ for different insulin pump systems available in Germany at the time of testing.

\section{Materials and Methods}

\section{Insulin pump systems}

Ten different insulin pump systems, that is, combinations of insulin pumps and IIS, were tested (Table 1). Five durable pumps with common IIS and one patch pump were included. All insulin pumps were prepared according to the respective manufacturers' instructions for use and filled with insulin aspart (NovoRapid ${ }^{\circledR}$; Novo Nordisk A/S, Bagsværd, Denmark). From each insulin pump system three individual insulin pumps were tested in three repetitions to obtain nine data sets (runs) per system.

\section{Test procedures}

Test setups and procedures were described in detail before. ${ }^{9}$ In short, accuracy was determined by means of weight differences through insulin delivery into a water-filled oilcovered beaker placed on a balance as described in IEC 60601-2-24. ${ }^{8}$ For the patch pump, the setup had to be modified due to the lack of an administration set. ${ }^{9}$

Bolus accuracy was determined for a standard bolus of 1 and $10 \mathrm{U}$. For the $1 \mathrm{U}$ bolus accuracy, 25 boluses were delivered and weighed individually. For the evaluation of the $10 \mathrm{U}$ bolus, only 12 boluses were delivered due to the limited reservoir size of some pump systems that would have required refilling, which might have influenced the results. In addition, delivery time for a $10 \mathrm{U}$ bolus was measured at standard speed settings with all systems. If a pump offered different bolus speed settings, all available speeds were tested, but only with one IIS per insulin pump.

Basal rate accuracy was determined for a constant basal rate of $1.0 \mathrm{U} / \mathrm{h}$. The basal rate was run for $72 \mathrm{~h}$ and weight increases measured every $15 \mathrm{~min}$ were used for calculations of the basal rate accuracy.

\section{Data analysis}

Bolus and basal rate delivery of U-100 insulin $(100 \mathrm{U} / \mathrm{mL})$ were calculated from weight increases, using a density of $1.005 \mathrm{~g} / \mathrm{mL}$ for insulin aspart. ${ }^{10}$

For each individual bolus, deviation from target (1 or $10 \mathrm{U}$, respectively) was calculated. In addition, the percentage of

Table 3. Bolus Delivery Time for 10 U Boluses WITH Different Bolus Delivery Speeds (MeAn of $N=9$ Boluses)

\begin{tabular}{lccccc}
\hline & $\begin{array}{c}\text { Standard } \\
\text { (min:s) }\end{array}$ & $\begin{array}{c}\text { Very } \\
\text { slow } \\
\text { (min:s) }\end{array}$ & $\begin{array}{c}\text { Slow } \\
\text { (min:s) }\end{array}$ & $\begin{array}{c}\text { Moderate } \\
\text { (min:s) }\end{array}$ & $\begin{array}{c}\text { Fast } \\
\text { (min:s) }\end{array}$ \\
\hline AI-F & $00: 50$ & $3: 20$ & $01: 40$ & $01: 07$ & - \\
AI-R & $00: 50$ & $-{ }^{\mathrm{a}}$ & $\mathbf{-}^{\mathrm{a}}$ & $-{ }^{-}$ & - \\
ASC-F & $00: 50$ & - & - & - & - \\
ASC-R & $00: 50$ & - & - & - & - \\
AV-I & $00: 20$ & - & $00: 52$ & - & - \\
M6-Q & $06: 38$ & - & - & - & $00: 40$ \\
MO & $06: 39$ & - & - & - & - \\
PV-M & $04: 58$ & - & - & - & - \\
PV-Q & $04: 58$ & - & - & - & - \\
PV-S & $04: 58$ & - & - & - & - \\
\hline
\end{tabular}

${ }^{\mathrm{a}}$ Not assessed with this insulin infusion set. 
Table 4. Basal Rate Accuracy (1.0 U/h): Total Deviation for Different Time Periods, Mean and Minimum and Maximum of Nine Repetitions

\begin{tabular}{lllr}
\hline Pump system & Total deviation $(0-72 h)$ & Total deviation $(0-12 h)$ & Total deviation $(12-72 h)$ \\
\hline AI-F & $0.0 \%(-0.52 \%$ to $0.70 \%)$ & $0.6 \%(-2.26 \%$ to $5.10 \%)$ & $-0.1 \%(-0.98 \%$ to $0.80 \%)$ \\
AI-R & $1.0 \%(-0.48 \%$ to $2.38 \%)$ & $0.1 \%(-4.10 \%$ to $4.63 \%)$ & $1.1 \%(-0.21 \%$ to $2.04 \%)$ \\
ASC-F & $-0.4 \%(-1.26 \%$ to $0.31 \%)$ & $3.7 \%(-1.87 \%$ to $10.31 \%)$ & $-1.3 \%(-1.73 \%$ to $-0.57 \%)$ \\
ASC-R & $0.2 \%(-0.81 \%$ to $0.73 \%)$ & $3.0 \%(1.36 \%$ to $4.38 \%)$ & $-0.3 \%(-1.25 \%$ to $0.12 \%)$ \\
AV-I & $0.0 \%(-0.58 \%$ to $0.47 \%)$ & $4.7 \%(1.72 \%$ to $6.71 \%)$ & $-0.9 \%(-1.66 \%$ to $-0.31 \%)$ \\
M6-Q & $0.9 \%(0.11 \%$ to $2.02 \%)$ & $9.9 \%(6.48 \%$ to $13.04 \%)$ & $-0.9 \%(-1.65 \%$ to $-0.19 \%)$ \\
MO & $1.4 \%(0.15 \%$ to $2.60 \%)$ & $5.0 \%(1.71 \%$ to $9.14 \%)$ & $0.6 \%(-0.31 \%$ to $1.58 \%)$ \\
PV-M & $-0.1 \%(-0.79 \%$ to $0.77 \%)$ & $1.7 \%(-1.28 \%$ to $3.30 \%)$ & $-0.5 \%(-1.12 \%$ to $0.26 \%)$ \\
PV-Q & $0.1 \%(-0.86 \%$ to $0.67 \%)$ & $2.9 \%(-2.83 \%$ to $6.51 \%)$ & $-0.5 \%(-0.96 \%$ to $-0.12 \%)$ \\
PV-S & $0.5 \%(-0.29 \%$ to $1.45 \%)$ & $2.9 \%(0.52 \%$ to $6.33 \%)$ & $0.1 \%(-0.47 \%$ to $0.59 \%)$ \\
\hline
\end{tabular}
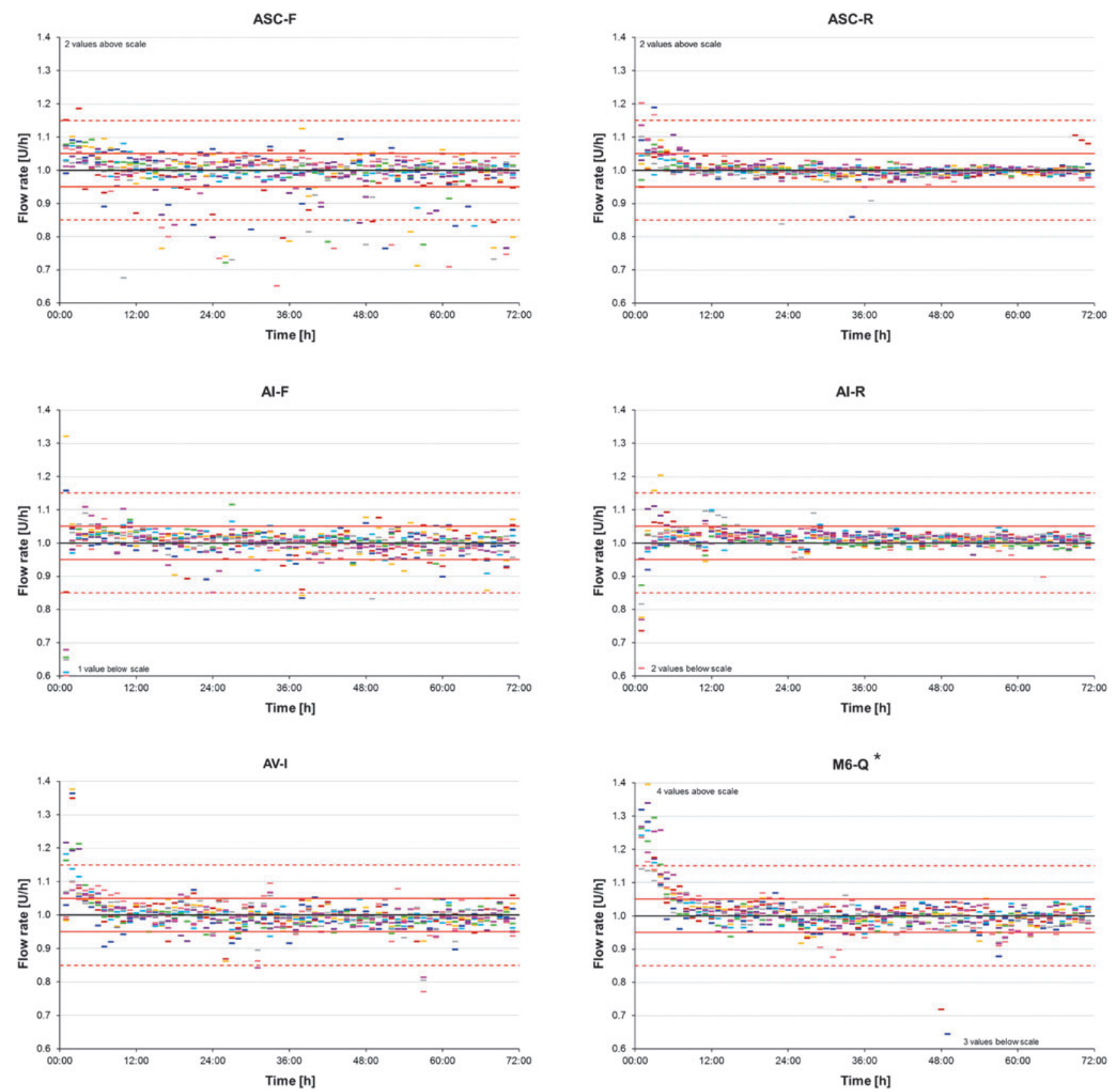

FIG. 3. Basal rate accuracy of $1-\mathrm{h}$ windows in the course of time for each insulin pump system. Colored dashes show the flow rate of 1 -h windows calculated from weight increases for the individual runs ( $n=71$ values for each of 9 runs), the black line shows the target rate $(1.0 \mathrm{U} / \mathrm{h})$, and red lines and red dashed lines show the $\pm 5 \%$ and $\pm 15 \%$ range, respectively. *The batch used in this study was recalled by the manufacturer (Medtronic reference FA785) after the investigation. 
boluses within different ranges from target $( \pm 15 \%, \pm 10 \%$, $\pm 5 \%$ ) was calculated. The $72 \mathrm{~h}$ of basal rate delivery was divided into $1-\mathrm{h}$ windows and deviation from target $(1.0 \mathrm{U} / \mathrm{h})$ was calculated for each 1-h window, and the percentage of 1 -h windows within different ranges from target $( \pm 15 \%$, $\pm 10 \%, \pm 5 \%$ ) was calculated. ${ }^{9}$ In addition, the total deviation for the whole $72 \mathrm{~h}$ and for the first $12 \mathrm{~h}$ was determined, respectively. Trumpet curves as required by IEC 60601-2-24 were generated by calculating the minimal and maximal deviation for observation windows of 15, 60, 150, 330,570 , and $930 \mathrm{~min}$, respectively, whereas the first $24 \mathrm{~h}$ were neglected.

Data from the nine data sets per insulin pump system were evaluated separately but summarized for data presentation. Data were analyzed descriptively; no comparative analyses between the tested insulin pump systems were performed.

\section{Results}

\section{Bolus accuracy and delivery time}

The mean deviation of the weighed $1 \mathrm{U}$ boluses ranged from $-2.4 \% \pm 2.8 \%$ to $+1.2 \% \pm 1.7 \%$ of the target delivery among all insulin pump systems and $77 \%-100 \%$ of all delivered boluses per system were within $\pm 15 \%$ of the intended bolus volume (Table 2 and Fig. 1). With all systems except for the patch pump MO, at least $95 \%$ of all $1 \mathrm{U}$ boluses were within $\pm 15 \%$ of target. With the mean values being similar between all tested pump systems, precision between the single boluses was slightly higher in PV-S (95\% range:
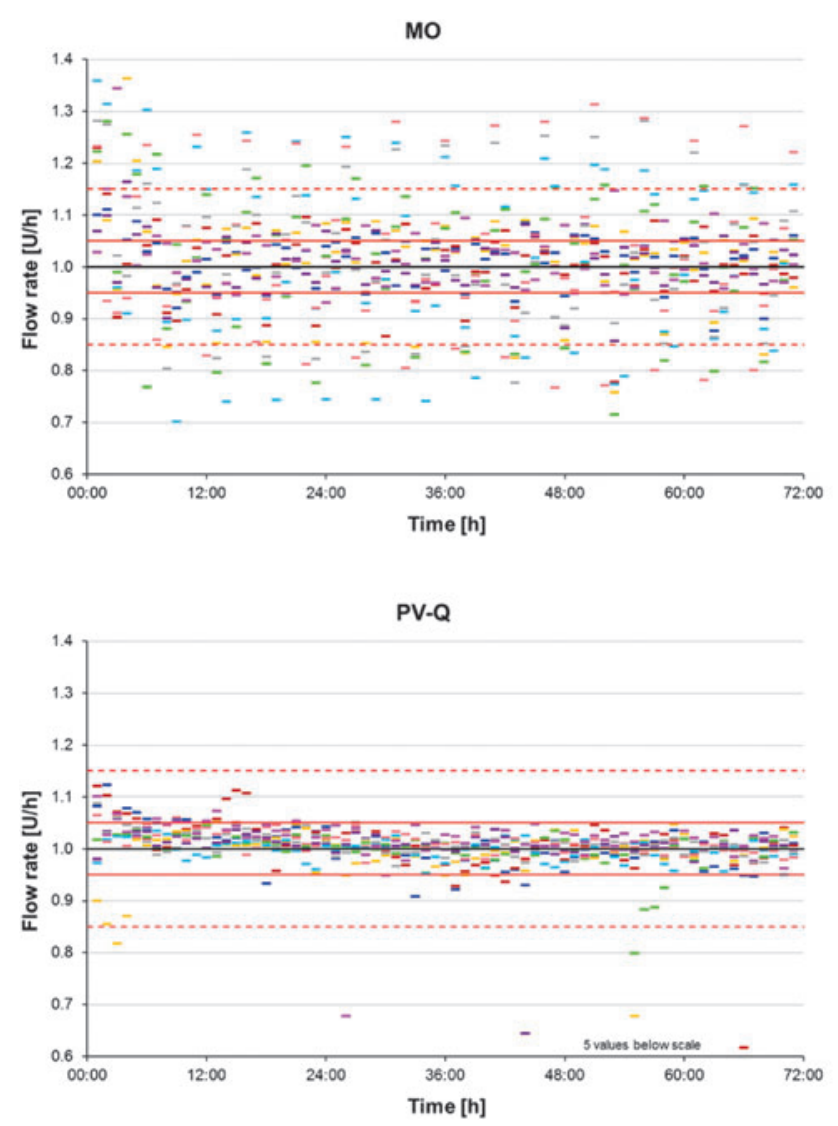

$0.06 \mathrm{U}$ ) and AV-I (95\% range: $0.07 \mathrm{U})$ than in the other pumps (95\% range from $0.08 \mathrm{U}$ to $0.52 \mathrm{U}$ ) (Fig. 1).

Upon delivery of $10 \mathrm{U}$ boluses, all measured boluses of all systems were within $\pm 5 \%$ of the intended bolus volume (Table 2 and Fig. 2).

Delivery times of a $10 \mathrm{U}$ bolus ranged from 00:20 min:s to 06:39 min:s in the different systems at standard bolus speed settings and were reproducible within each system (Table 3). Standard speed was fastest for AV-I and slowest for M6-Q and MO; however, M6-Q also offered a faster option.

\section{Basal rate accuracy}

The total deviation of the measured weight increase at the set basal rate of $1.0 \mathrm{U} / \mathrm{h}$ after $72 \mathrm{~h}$ was very small (between $-0.1 \%$ and $1.4 \%$ ) for all tested insulin pump systems (Table 4). During the first $12 \mathrm{~h}$, larger deviations of up to $10 \%$ were observed. Most pumps showed an increased delivery at the beginning of the measurement that gradually decreased during the first 6-12 h. Although during the first $12 \mathrm{~h}$, small differences between the individual systems could be seen with deviations ranging from $0.1 \%$ to $9.9 \%$, differences were marginal afterward. For those insulin pumps that were tested with different IIS, no influence of the used IIS on delivery accuracy was observed.

Figure 3 shows the calculated flow rate for the individual hours in the course of time for each repetition. A certain run-in time with larger deviations was observed for most systems, but to different degrees. It was most obvious for AV-I and M6$\mathrm{Q}$ indicating initial overdelivery; AI-F and AI-R, however,
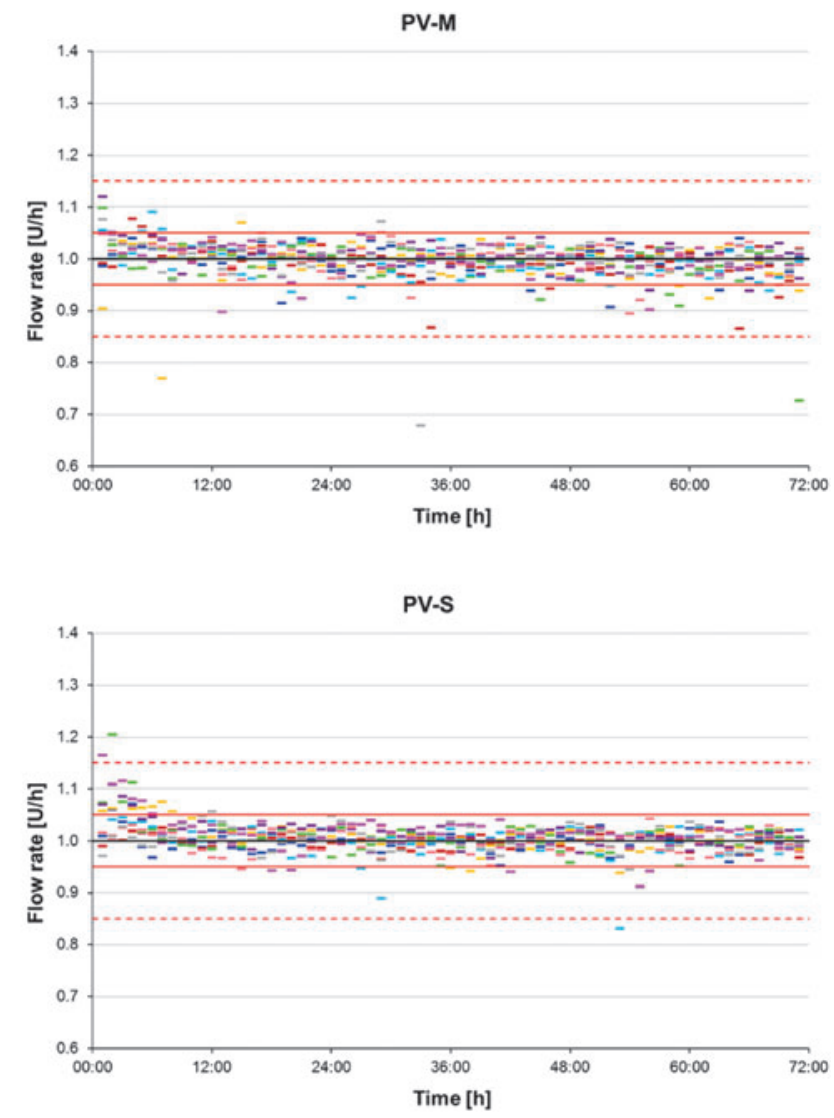

FIG 3. (Continued) 
rather showed initial underdelivery. ASC-F showed a biased scattering toward negative deviations during the whole test period. The highest precision was shown by ASC-R, whereas MO showed periodically alternating larger deviations that seemed to repeat after $\sim 5 \mathrm{~h}$ or $5 \mathrm{U}$ (Figs. 3 and 4 ).

In general, individual runs of each insulin pump system were comparable with the exception of MO, which showed the described large amplitude in four of the nine runs. Means of all 1-h windows were within $\pm 2 \%$ in all systems, and for 7 of the 10 systems $\geq 95 \%$ of 1 -h windows were within $\pm 15 \%$ of the intended basal rate (Fig. 4 and Table 5).

Trumpet curves for all pump systems as required by IEC 60601-2-24 are shown in Supplementary Figure S1.

\section{Discussion}

In this comparative in vitro evaluation of insulin pump accuracy, 10 insulin pump systems, including 6 different pump models, were tested. To our knowledge, this is the largest comparison of insulin pumps tested in parallel published so far, the used methods were described and discussed in detail before. ${ }^{9}$ Factors such as the so-called siphon effect, ${ }^{11}$ infusion set changes, ${ }^{12}$ or pressure variations, which might have influenced the results or alleviated the inherent differences between the pumps, were avoided as far as possible. In practice, the tested insulin pumps might not be equally sensitive to these factors.

This study investigated accuracy at an intermediate basal rate and bolus doses as they might be used in adult CSII patients. Although the assumption that accuracy is higher the larger the delivered volume is could be confirmed in this study for two different bolus doses, the study results might not be transferable to all other bolus sizes or basal rates. There are no mandatory accuracy requirements or acceptance criteria for insulin pumps; however, under the assumption that a mean total deviation from target of $\pm 5 \%$ is acceptable, all systems showed a good performance. At least for a $1.0 \mathrm{U} / \mathrm{h}$ basal rate, most manufacturers of the systems also describe an accuracy of $\pm 5 \%$ in the respective manuals. Also, delivery time of a $10 \mathrm{U}$ standard bolus in all pump systems complied with the delivery speeds given in the respective manuals. It has to be considered, however, that the described times differ between the particular insulin pump models, that is, that "standard" refers to a pumpspecific feature that might be very fast in some and rather slow in other pump models. For pumps with adjustable bolus speed, for example, "standard" was the fastest of the options in AI and AV, whereas it was the slowest option in M6.

Variations between the individual pumps can only be seen when considering additional data beyond mean values. For bolus accuracy, this could be the evaluation of each single bolus instead of only the mean of several boluses, because this reflects the usage of boluses in clinical practice much better. In addition, variability between individual devices of the same model and IIS should be considered. Precision of single boluses was higher for the $10 \mathrm{U}$ bolus, but also with $1 \mathrm{U}$, all boluses of most systems were within $\pm 15 \%$ of the intended volume. One $1 \mathrm{U}$ bolus each of AV-I and PV-Q, and several boluses of MO were outside these limits, but since these were evenly distributed in terms of negative and positive deviations, this could not be seen in the mean deviation. Using other methods, a high bolus delivery accuracy for MO was reported. ${ }^{4}$ Large differences between single boluses could be an issue in clinical practice for patients, as at one time an overdelivery and at the next time an underdelivery may lead to very different glycemic outcomes after the given bolus without being comprehensible for the patient.

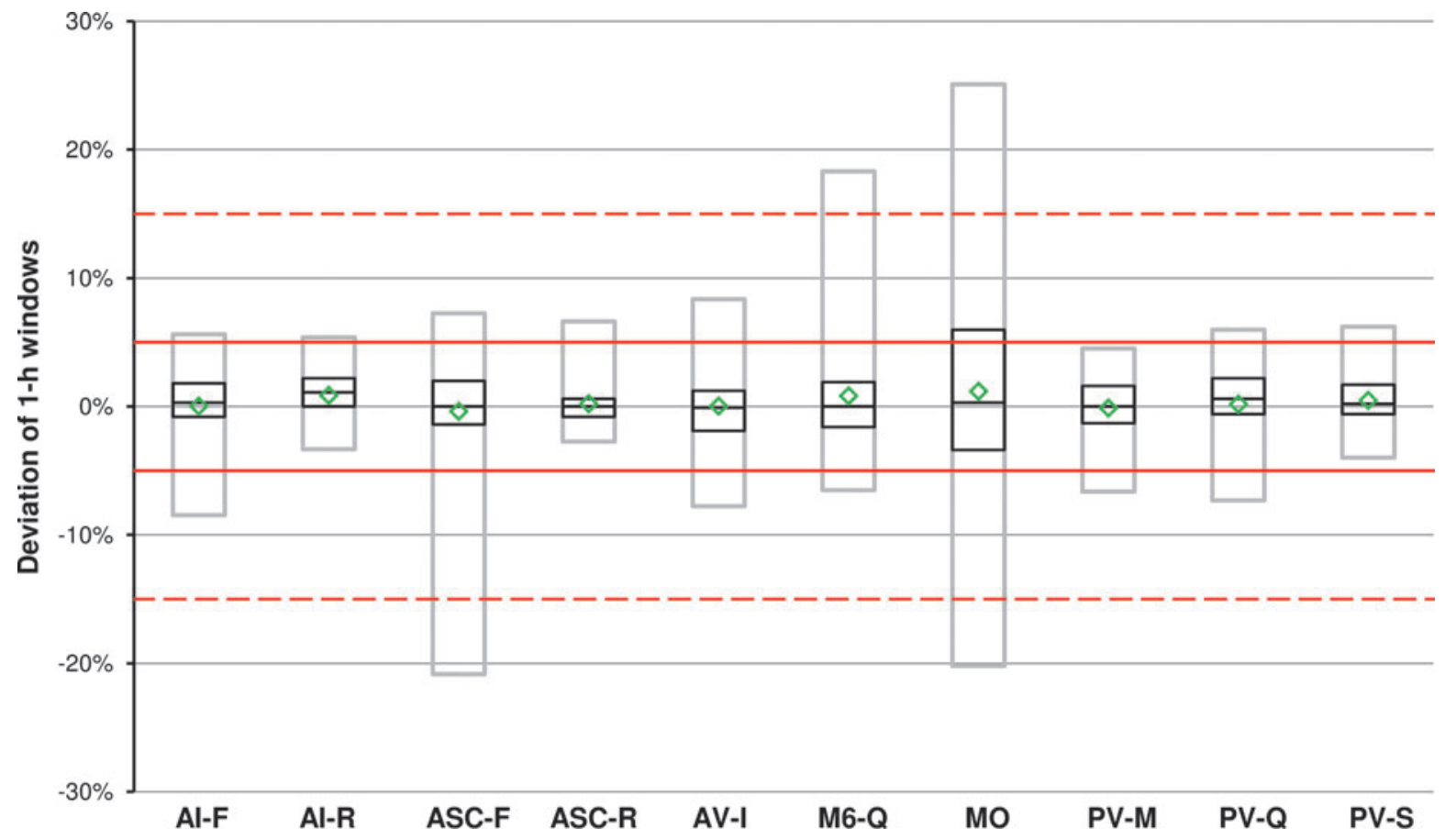

FIG. 4. Basal rate accuracy of 1 -h windows of all insulin pump systems at $1.0 \mathrm{U} / \mathrm{h}$. For each system, mean (green diamonds), median with first and third quartile (black boxes), and 95\% range (gray boxes) are shown ( $n=648$ values). Red lines and red dashed lines indicate target $\pm 5 \%$ and target $\pm 15 \%$, respectively. 
Table 5. Basal Rate (1.0 U/H) Accuracy: Percentage of 1-H Windows Within Different Deviation Thresholds $(N=693$ Values $)$

\begin{tabular}{lccc}
\hline $\begin{array}{l}\text { Pump } \\
\text { system }\end{array}$ & $\begin{array}{c}\text { 1-h windows } \\
\text { within } \pm 15 \% \\
(\%)\end{array}$ & $\begin{array}{c}\text { 1-h windows } \\
\text { within } \pm \text { 10\% } \\
(\%)\end{array}$ & $\begin{array}{c}\text { 1-h windows } \\
\text { within } \pm 5 \% \\
(\%)\end{array}$ \\
\hline AI-F & 98.3 & 96.7 & 89.2 \\
AI-R & 98.4 & 97.8 & 94.5 \\
ASC-F & 93.7 & 91.5 & 80.6 \\
ASC-R & 99.4 & 98.6 & 94.8 \\
AV-I & 97.8 & 96.4 & 85.4 \\
M6-Q & 95.6 & 93.1 & 84.0 \\
MO & 81.2 & 71.2 & 46.6 \\
PV-M & 99.5 & 98.7 & 92.6 \\
PV-Q & 98.3 & 96.7 & 89.8 \\
PV-S & 99.5 & 98.7 & 93.9 \\
\hline
\end{tabular}

Regarding basal rate accuracy, the total mean deviation is helpful to identify a possible general bias, but details such as whether delivery is constant over time or accuracy within shorter periods are missing. The first aspect was taken into account by dividing the total measurement period into different phases and comparing the mean deviation of these. Most obvious was the course of deviations during the first $12 \mathrm{~h}$ of the experiment. Although all systems were correctly installed and primed, for most of the tested systems, a clear run-in phase with less accurate delivery was observed. Commonly, this run-in phase was characterized by an overor underdelivery that decreased with increasing run time, but duration and extent of the run-in were not specifically quantified in this study. Some pump systems, in particular ASC-R, AV-I, M6-Q, MO, and PV-S, showed a clear tendency toward an initial overdelivery, whereas AI-R showed initial underdelivery and for AI-F, ASC-F, PV-M, and PV-Q no clear conclusion could be drawn. Accordingly, in the first $12 \mathrm{~h}$ absolute deviations from the expected rate were larger than in the following $60 \mathrm{~h}$. In a clinical setting, the first $12 \mathrm{~h}$ would be as important for the patient as the following $60 \mathrm{~h}$ and patients often anecdotally report changes in their glycemic control immediately after a change of the insulin pump system. One might argue that the test setting affected the runin phase, but since the different pumps behaved differently within the same setting, it is likely caused by the specific insulin pump. Jahn et al. showed an initial underdelivery for all pumps tested in their study. ${ }^{5}$ For bolus delivery, no pattern of less accurate delivery during the first boluses of a series was observed.

Deviation of individual 1 -h windows gives information about the continuity and accuracy for shorter time. A certain "oscillation" may be assumed among all pumps, as the measurement frequency might not have fit the interval of single basal rate bursts given by all pumps. However, most systems showed only a few 1 -h windows outside a $\pm 15 \%$ range, as already reported by Borot et al. ${ }^{6}$ The pronounced differences between individual 1-h windows of the patch pump MO are most likely due to pump-specific characteristics. Similar results, that is, large deviations between single doses of this pump were already observed by others. ${ }^{5,6}$

Trumpet curves as required by IEC 60601-2-24 were also provided; however, these curves might be misleading as they are often misunderstood. ${ }^{13}$ In addition, they exclude the first $24 \mathrm{~h}$ of delivery and only provide minimal and maximal deviations that might not be representative for the majority of values.

Knowledge about the impact of insulin delivery accuracy is limited; to our knowledge, there are no clinical studies that specifically investigated the effects of dosing errors on clinical outcomes. However, there are simulation studies for glucose measurement errors ${ }^{14,15}$ and clinical studies for carbohydrate counting errors ${ }^{16,17}$ that might lead to the assumption that dosing errors of $>15 \%$ to $20 \%$ might have a clinical impact. A recent simulation study ${ }^{18}$ about the minimum insulin dose required for clinically meaningful changes in glucose concentrations suggests that this clinical impact may already be visible with basal rate changes of $0.1 \mathrm{U} / \mathrm{h}$ or bolus doses of $0.3 \mathrm{U}$ for a time span of $4 \mathrm{~h}$. With this study, the magnitude of insulin dosing errors was quantified; and similar model calculations based on these results, and possibly also for shorter time spans, could be helpful to quantify the clinical effects.

Whether the differences between the pumps and infusion sets observed in this study will also be noticed by patients when using the pumps will have to be addressed in further investigations. Likewise, the impact of different environmental factors that arise during use in practice on delivery accuracy should be studied.

This study has some limitations. First, comparability between the patch pump and the durable pumps is still limited due to different test setups, although an adequate setup for patch pumps was established in a prestudy. ${ }^{9}$ In addition, not for all durable pumps entirely comparable IIS were available. However, the obtained data do not indicate a profound influence of the particular IIS.

Basal rate accuracy results for M6-Q have to be regarded with caution, because after the tests were finished, the used batch of the infusion set was recalled by the manufacturer. The reason was a possible overdelivery in case liquid reaches the connection between IIS and cartridge during the priming process. It cannot be excluded that the initial deviations observed for M6-Q were caused by such a failure; however, measurements were not repeated since the recall came after the test and, therefore, at the time of the test, the used system reflected one that could also have been used by a patient.

Results of this study comply with those of other comparative studies in which, even if performed with variations in methodology, tested durable pumps showed a higher level of accuracy, especially when regarding short-term basal rate accuracy, than the patch pump tested in this study. ${ }^{5,6}$ However, in this study rather large doses were evaluated and with smaller doses, accuracy is expected to be lower.

\section{Conclusion}

This technical evaluation of insulin pump accuracy regarding insulin delivery at medium bolus doses and basal rate showed that, in general, all compared systems showed a similar level of accuracy. Differences, especially between durable pumps and the patch pump, were observed when considering each hour of delivery separately.

\section{Acknowledgments}

The authors thank the testing laboratory that independently performed measurements and Stefan Pleus (IDT) for his input 
in discussing the results. Funding: Performance of the study and scientific writing were funded by Roche Diabetes Care, Germany.

\section{Author Disclosure Statement}

G.F. is general manager of the IDT (Institut für DiabetesTechnologie, Forschungs- und Entwicklungsgesellschaft $\mathrm{mbH}$ an der Universität Ulm, Ulm, Germany), which carries out clinical studies on the evaluation of BG meters and medical devices for diabetes therapy on its own initiative and on behalf of various companies. G.F./IDT has received speakers' honoraria or consulting fees from Abbott, Ascensia, Bayer, Dexcom, LifeScan, Menarini Diagnostics, Metronom Health, Novo Nordisk, Roche, Sanofi, Sensile, and Ypsomed. U.K., D.W., and C.H. are employees of the IDT. R.Z. has received speaker's honoraria and/or served on advisory boards from/of Abbott, Animas, Ascensia, AstraZeneca, Lilly, Novo Nordisk, and Roche Diabetes Care.

\section{Supplementary Material}

Supplementary Figure S1

\section{References}

1. Grunberger G, Abelseth JM, Bailey TS, et al.: Consensus Statement by the American Association of Clinical Endocrinologists/American College of Endocrinology insulin pump management task force. Endocr Pract 2014;20: 463-489.

2. Thabit H, Hovorka R: Continuous subcutaneous insulin infusion therapy and multiple daily insulin injections in type 1 diabetes mellitus: a comparative overview and future horizons. Expert Opin Drug Deliv 2016;13:389-400.

3. Keith K, Nicholson D, Rogers D: Accuracy and precision of low-dose insulin administration using syringes, pen injectors, and a pump. Clin Pediatr (Phila) 2004;43:69-74.

4. Zisser H, Breton M, Dassau E, et al.: Novel methodology to determine the accuracy of the OmniPod insulin pump: a key component of the artificial pancreas system. J Diabetes Sci Technol 2011;5:1509-1518.

5. Jahn LG, Capurro JJ, Levy BL: Comparative dose accuracy of durable and patch insulin infusion pumps. J Diabetes Sci Technol 2013;7:1011-1020.

6. Borot S, Franc S, Cristante J, et al.: Accuracy of a new patch pump based on a microelectromechanical system (MEMS) compared to other commercially available insulin pumps: results of the first in vitro and in vivo studies. J Diabetes Sci Technol 2014;8:1133-1141.

7. Bowen JL, Allender CJ: A comparative pulse accuracy study of two commercially available patch insulin infusion pumps. Eur Endocrinol 2016;12:79-84.
8. Medical electrical equipment-part 2-24: particular requirements for the safety of infusion pumps and controllers (IEC 60601-2-24:1998), 1998.

9. Kamecke U, Waldenmaier D, Haug C, et al.: Establishing Methods to Determine Clinically Relevant Bolus and Basal Rate Delivery Accuracy of Insulin Pumps. J Diabetes Sci Technol 2019;13:60-67.

10. Ward LG, Heckman MG, Warren AI, Tran K: Dosing accuracy of insulin aspart FlexPens after transport through the pneumatic tube system. Hosp Pharm 2013;48:33-38.

11. Zisser HC, Bevier W, Dassau E, Jovanovic L: Siphon effects on continuous subcutaneous insulin infusion pump delivery performance. J Diabetes Sci Technol 2010;4:98-103.

12. Zisser H: Quantifying the impact of a short-interval interruption of insulin-pump infusion sets on glycemic excursions. Diabetes Care 2008;31:238-239.

13. Pleus S, Kamecke U, Waldenmaier D, Freckmann G: Reporting Insulin Pump Accuracy: trumpet Curves According to IEC 60601-2-24 and Beyond. J Diabetes Sci Technol 2018:1932296818806509.

14. Breton MD, Kovatchev BP: Impact of blood glucose self-monitoring errors on glucose variability, risk for hypoglycemia, and average glucose control in type 1 diabetes: an in silico study. J Diabetes Sci Technol 2010; 4:562-570.

15. Kovatchev BP, Patek SD, Ortiz EA, Breton MD: Assessing sensor accuracy for non-adjunct use of continuous glucose monitoring. Diabetes Technol Ther 2015;17:177-186.

16. Smart CE, King BR, McElduff P, Collins CE: In children using intensive insulin therapy, a 20 -g variation in carbohydrate amount significantly impacts on postprandial glycaemia. Diabet Med 2012;29:e21-e24.

17. Deeb A, Al Hajeri A, Alhmoudi I, Nagelkerke N: Accurate carbohydrate counting is an important determinant of postprandial glycemia in children and adolescents with type 1 diabetes on insulin pump therapy. J Diabetes Sci Technol 2017;11:753-758.

18. Campos-Nanez E, Layne JE, Zisser HC: In silico modeling of minimal effective insulin doses using the uva/ padova type 1 diabetes simulator. J Diabetes Sci Technol 2018;12:376-380.

Address correspondence to: Guido Freckmann, MD Institut für Diabetes-Technologie Forschungs- und Entwicklungsgesellschaft $\mathrm{mbH}$ an der Universität Ulm Lise-Meitner-Straße 8/2 Ulm 89081 Germany

E-mail: guido.freckmann@idt-ulm.de 